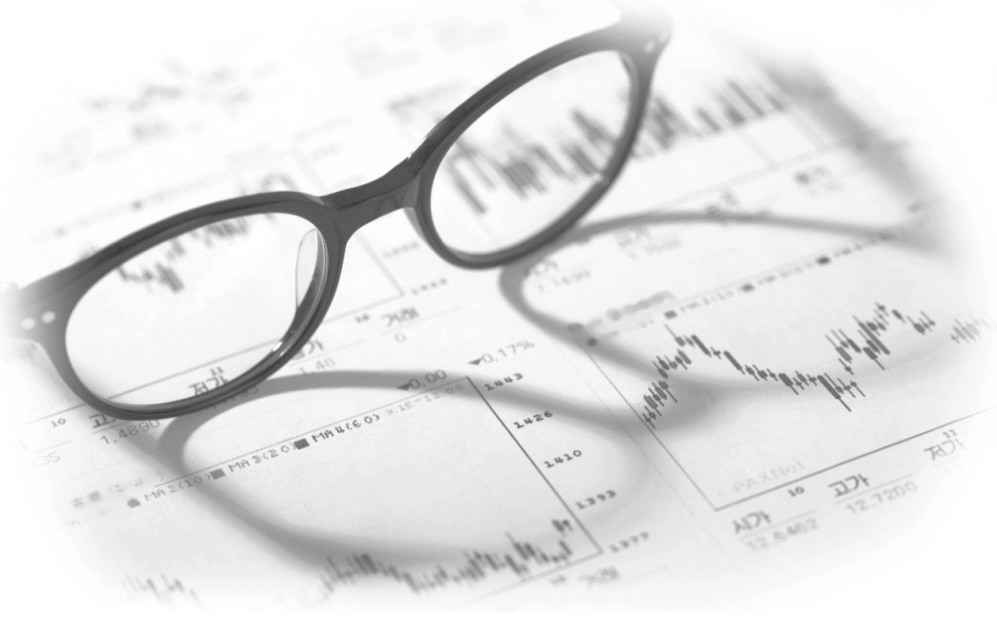

http://dx.doi.org/10.5045/kjh.2012.47.3.159

The Korean Journal of Hematology Volume 47 • Number 3 - September 2012 Perspective

\section{Celebrating the World Blood Donor Day 2012}

\author{
Sunhee Kim
}

2012 World Blood Donor Day Secretariat, Blood Service HQs, Korean Red Cross, Seoul, Korea

Blood transfusion saves lives and improves health, but not every country in the world provides an adequate environment for promoting safe transfusion. According to the World Health Organization (WHO)'s blood safety fact sheet, there is a huge difference in the number of blood donations between countries with high and low incomes. Approximately 92 million blood donations are collected each year, half of which were made in high-income countries, which comprise only $15 \%$ of the world's population. In 2008, $100 \%$ of national blood supplies were sourced through voluntary unpaid blood donations in only 62 countries. Another 40 countries collected less than a quarter of their blood supplies from voluntary unpaid blood donors. To the astonishment of many, 39 countries were not able to screen all donated blood for 1 or more of HIV, hepatitis B, hepatitis $\mathrm{C}$, and syphilis. In Korea, more than 30 blood donations per 1,000 people were made in 2008 , of which $100 \%$ were voluntary unpaid blood donations. These statistics are well above the average for other Asian countries and parallel to those in other high-income developed countries. Korea is continuously putting efforts in ensuring and improving safety in blood donation and transfusion.

Realizing that blood safety is the index of public health, the WHO and the International Federation of Red Cross and Red Crescent Societies (IFRC) have worked hard for years to promote voluntary unpaid blood donations around the world. In company with the International Federation of Blood Donor Organizations (IFBDO) and the International Society of Blood Transfusion (ISBT), the WHO and the IFRC have created a special day to pay tribute to those people worldwide who give their blood freely and anonymously so that the lives of many patients can be saved.

At the $58^{\text {th }}$ World Health Assembly, the WHO designated the World Blood Donor Day (WBDD) as an annual event to be held each year on June 14. This is a day to inspire people to express gratitude for those who donate blood voluntarily and to encourage both voluntary donors and others who give blood regularly. This day is also intended to promote national voluntary programs, thereby eliminating dependency on family members and paid donors, and to raise awareness of the need for regular blood donation throughout the year in order to maintain adequate supplies for patients requiring transfusions.

Since the first WBDD in 2004 in Johannesburg, South Africa, this day has become an enormously successful worldwide festival that is celebrated in many countries. Various activities to show appreciation to regular voluntary donors and raise awareness regarding the importance of blood donation are conducted. These activities help to increase public interest by emphasizing the importance of voluntary non-remunerated blood donation via global campaigns.

The theme of the WBDD 2012 campaign was "Every blood donor is a hero," focusing on the idea that everyone can become a hero by giving blood. This theme recognizes the silent and unsung heroes who save lives every day through their blood donations and also strongly encourages more people to donate blood voluntarily and regularly.

As the host country of WBDD 2012, Korea organized events that were focused on recognizing voluntary blood donors' noble actions and encouraging unpaid voluntary blood donations around the world. As the host organization of this global event, the Korean Red Cross (KRC) began

This is an Open Access article distributed under the terms of the Creative Commons Attribution Non-Commercial License (http://creativecommons.org/licenses/by-nc/3.0) which permits unrestricted non-commercial use, distribution, and reproduction in any medium, provided the original work is properly cited. 


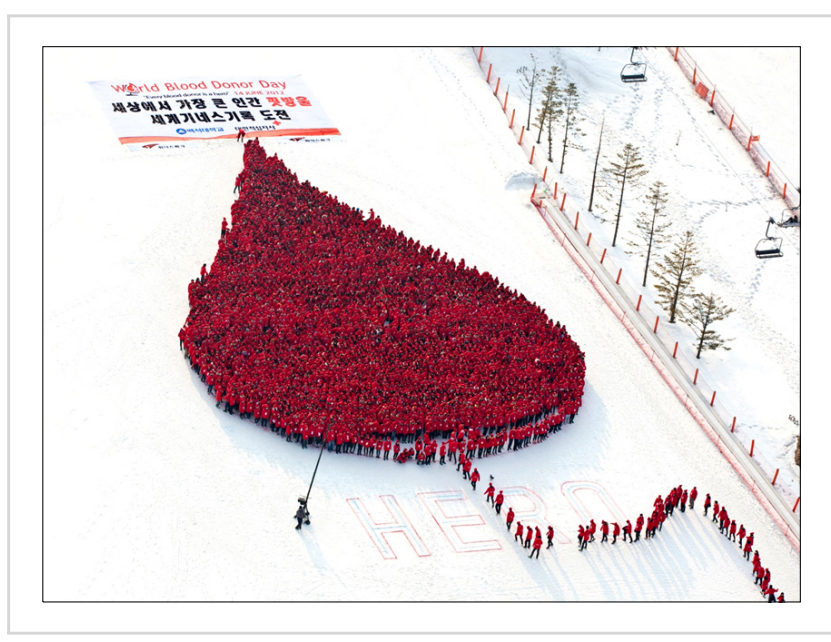

Fig. 1. The largest ever human blood-drop, made up of 3,006 students and faculty members of the Baekseok University in February, 2012. It won the Guinness World Record.

a series of WBDD 2012 celebrations by creating the largest "human blood-drop" in the world. A total of 3,006 students and faculty members from the Baekseok University, all current and future blood donors, got together at a ski slope in February and created the "human blood drop." It won the Guinness World Record title for "The largest human blood-drop" (Fig. 1).

In another celebration of WBDD 2012, an "Every Blood Donor is a Hero" event took place at Cheonggye Square, Seoul on April 27. More than 1,000 citizens, including 100 children, who were invited by the KRC, participated in various events such as an OX quiz show, a photo zone, a message board, a puppet show, and a donation ceremony for a vehicle for mobile blood collection. Events that involve children and that raise their awareness of blood donation are important because they can help in promoting future blood donations for the next generation. They were educated regarding blood donations, and paper boats were set sail to show support for reaching a blood donor population of 3 million in Korea. The festival was filled with joy, and citizens learned what blood donations can give them.

At the commemorative ceremony of the WBDD 2012 Global Event, representatives of 4 founding international organizations including the WHO, IFRC, IFBDO, and ISBT, joined the minister of Health and Welfare of Korea and the President of KRC to pay tribute to the tireless dedication of blood donors, not just in Korea, but all across the world. The ISBT representative said "But we are still heroes through our own quiet simple 'heroic acts', whether it be extending a helping hand to those less fortunate than us, championing a cause we are passionate about, or spending an hour of our time donating blood. Every blood donor is a hero and today on WBDD we celebrate our heroes." At the ceremony, individual blood donors as well as representatives from the corporate, public, and private sectors were recognized as heroes in practicing social responsibility.

Later in the day, at the scientific symposium, blood experts from around the world joined the staff and volunteers involved in blood service delivery and shared their experiences and international perspectives on the self-sufficiency of blood and blood products based on voluntary unpaid blood donation.

In addition to the symposia and commemorative ceremonies, Korea hosted other WBDD celebratory events. Ceremonial first pitches by blood donation heroes at a Korean baseball game were featured all over the nation. Famous baseball players became the PR envoys for blood donation, and the appointment ceremony was held after the match. Furthermore, the country's main bridges and the Seoul Namsan Tower shone in brilliant red lights to commemorate this special day. The campaign evoked the citizens' empathy towards the importance and necessity of blood donation and raised awareness regarding the heroic, life-saving action among the next generation of blood donors.

The day's celebration ended with a special dinner hosted by the Prime Minister of Korea. He invited all the foreign guests and awardees, expressed sincere gratitude to blood donors for their heroic gesture, and encouraged them to participate in blood donation regularly.

Finally, the series of WBDD 2012 celebrations ended with a concert for blood donors. Invited guests, including 1,000 blood donors, watched famous K-pop (Korean pop) celebrities including Super Junior and Wonder Girls celebrate the joy of blood donation together.

Overall, the WBDD 2012 campaign in Korea was a huge success in presenting the importance of safety in transfusion, promoting and appreciating unpaid voluntary blood donation, and emphasizing the importance of blood policy and processing. Next year, this global celebration to thank those who give so selflessly moves on to Paris.

Every blood donor is a hero. You too can become one! 